\title{
Seed germination of native plants in soil transformed by invasive plants Acer negundo and Heracleum sosnowskyi
}

\author{
Olesya Rafikova ${ }^{1}$, Olga Kiseleva ${ }^{2, *}$, and Denis Veselkin ${ }^{3}$ \\ ${ }^{1,3}$ Institute of Plant and Animal Ecology, UB RAS, 620144, Yekaterinburg, Russia \\ ${ }^{2}$ Institute Botanic Garden, UB RAS, 620144, Yekaterinburg, Russia
}

\begin{abstract}
We tested the hypothesis of the effect of soils transformed by invasive plants (Acer negundo L. and Heracleum sosnowskyi Manden.) on native plants germination. We conducted vegetation experiments in germination of Festuca rubra L. and Trifolium repens L. in upper layer of urban soil collected in invasive plants thickets and in nearby areas without invasive plants in 2016-2017. We also used the sod-podzolic soil from old suburban meadow as a control. Differences in seed germination on soils transformed by invasive plants and non-transformed soils were insignificant. We could not confirm the effect of soils collected from Acer negundo and Heracleum sosnowskyi thickets on plants germination by GLM analysis.
\end{abstract}

\section{Introduction}

The plant invasion can biochemically affect the species of native communities [1]. It might be resulted by resource competition and influence on other plants by releasing compounds that interfere directly to their growth $[1,2,3]$ or influence in other ways $[4,5,6]$.

That can be the part of plant-soil feedbacks - processes where plants alter the biotic and abiotic properties of soil they grow in, which then alters the ability of plants to grow in that soil [7]. It is considered that study of plant-soil feedback effects and mechanisms could allow to predict the consequences of plant-plant interactions [8].

The purpose of our work was to assess the influence of soils from dense thickets of two invasive plants on seed germination of two native plants. The hypothesis is that germination of native plants should be lower in soils that were transformed by invasive plants than on nonimpacted soils. In case of confirmation of hypothesis such effect could be considered as one way of environment-forming influence and competitive success of invasive plants.

There are known estimates of direct allelopathic influence concerning both studied invasive plants - Acer negundo L. and Heracleum sosnowskyi Manden. Researches of allelopathic activity $A$. negundo were conducted using water extracts from shoots, leaves and soils $[9,10,11]$ and in general, the extracts from $A$. negundo and from underlying soils

\footnotetext{
*Corresponding author: kiselevaolga@inbox.ru
} 
suppress development of test plants. The allelopathic activity of $H$. sosnowskyi can be caused by diversity and high content of its secondary metabolites - furocoumarins such as angelicin, bergapten, xanthoxin, umbelliferone, sphondin [12].

Earlier the allelopathic activity both extracts from separate organs of $H$. sosnowskyi [13, $14,15]$ and activity of individual chemical substance was investigated [15]. In general, it is considered that the allelopathic activity of $H$. sosnowskyi compounds exists. It is appearingly most strongly caused by angelicin [15] and it appears to be highly volatile [14, $16]$.

The question whether substances that capable to affect native plants could accumulate in upper layer of soils under the canopy of $A$. negundo and $H$. sosnowskyi has not been raised before. However, given the fact that allelopathic mechanisms for invasion of A. negundo and $H$. sosnowskyi are very likely, this question is justified.

\section{Material and methods}

\subsection{Study area}

All experimental sites were located on the territory of the city agglomeration of Yekaterinburg in the Sverdlovsk region. The height of Yekaterinburg above sea level is 270 meters, coordinates $56^{\circ} 50^{\prime} \mathrm{N} 60^{\circ} 35^{\prime} \mathrm{E}$. Yekaterinburg is a large industrial city in the Middle Ural with an area of about 49.8 thousand ha and the population of about 1.4 million inhabitants. The territory of Yekaterinburg is considered highly polluted due to both the presence of a large number of industrial enterprises and the impact of the high density of the road network.

The city of Yekaterinburg is located in the zone of the southern taiga. The city possesses a humid continental climate. It is characterized by long and cold winters with stable snow cover, as well as short summers. It is characterized by sharp variability in weather conditions, with well-marked seasons. The average annual temperature is $+3^{\circ} \mathrm{C}$, the average July temperature is $+19^{\circ} \mathrm{C}$, and the average January temperature is $-12.6^{\circ} \mathrm{C}$. The average frost-free period, which usually lasts from June to September, is 80-90 days in the mountains and about 90 days in the foothills. The snow-cover duration is from 150-160 to 180-190 days.

The city is in a zone of sufficient moisture. The average annual rainfall is $550-650 \mathrm{~mm}$. The maximum rainfall occurs during the warm season, during which about $60-70 \%$ of the annual amount falls.

\subsection{Invasive plants}

The soils for germination of native plants were collected on territory of urban agglomeration of the Yekaterinburg city in thickets of two invasive plants. Acer negundo L. (ash-leaved maple) is a North American woody plant from Sapindaceae family (Fig. 1); Heracleum sosnowskyi Manden. (Sosnowsky's hogweed) - large North Caucasus herbaceous plant from Apiaceae family (Fig. 2). Both of them are listed in Black Book of flora of Central Russia [17]. 


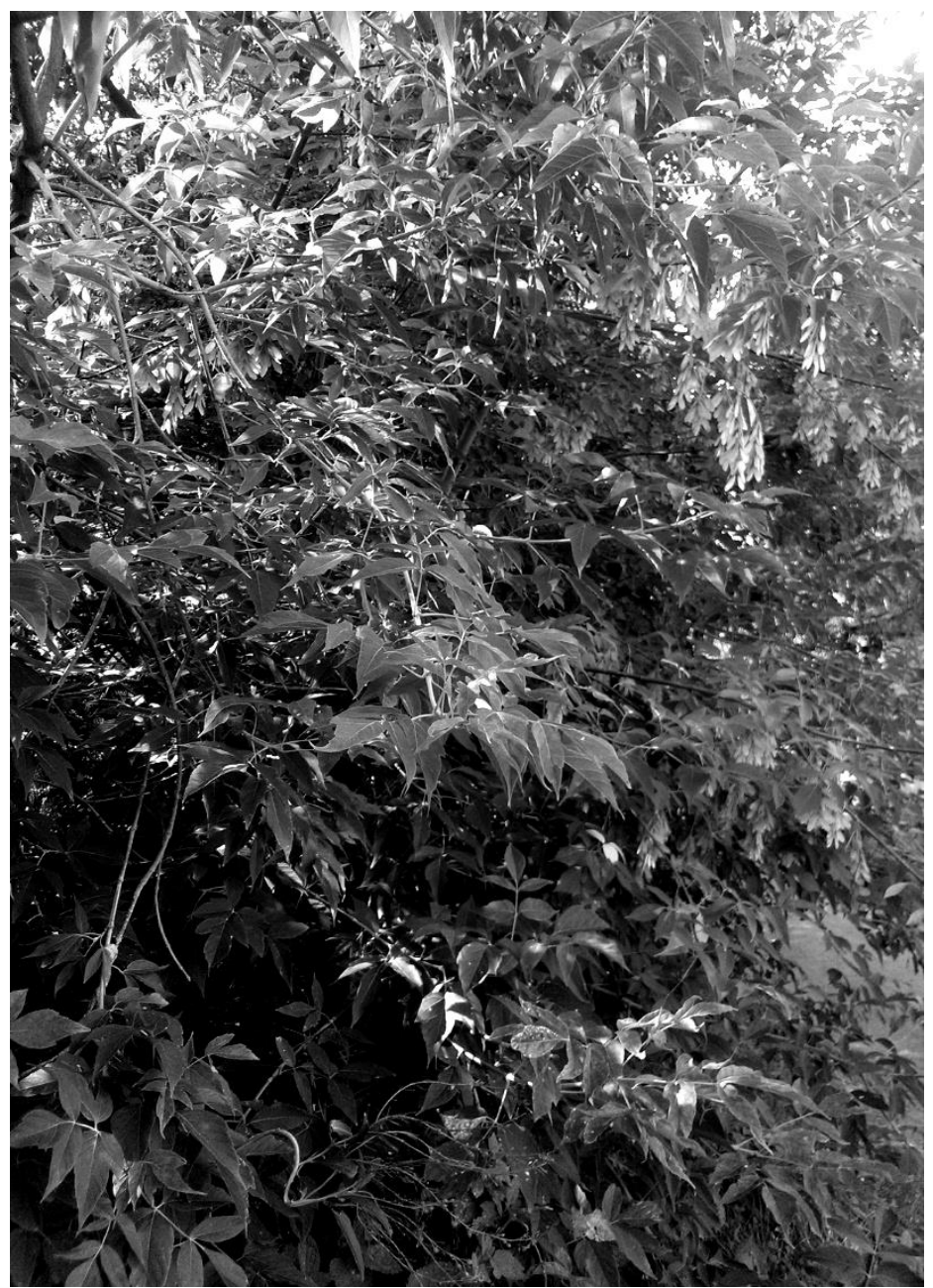

Fig. 1. Dense thickets of invasive plants Acer negundo in transformed habitat, Yekaterinburg city.

Both species are capable to form dense, almost one-specific thickets or curtains in the disordered or ecoton habitats. A. negundo can invade forest ecosystems, followed by roadsides, farmlands, and grasslands, riparian zones, and also it forms Acer-dominated forest communities on the place of former riparian communities [18]. It recognized as the first species in a list of the most invasive plants of Russia [17].

The most sites in which research on $A$. negundo invasion was studied according to the review of its invasions focusing on the Scopus and Web of Science databases are located in Europe [18]. Sosnowsky's hogweed has global importance in Russia because it becomes widespread in huge areas killing grass sod, replacing grasses, ensilage crops, medicinal plants, it is harmful to people through photochemical burns by photoactive sap containing plant furocoumarins and causes phytophotodermatitis [12]. In Russia and other countries of Eastern and Northern Europe, the invasions of $A$. negundo and $H$. sosnowskyi bring great economic damage. The studies of suitability for use both species in phytoremediation and biomass production are being conducted $[19,20]$. 


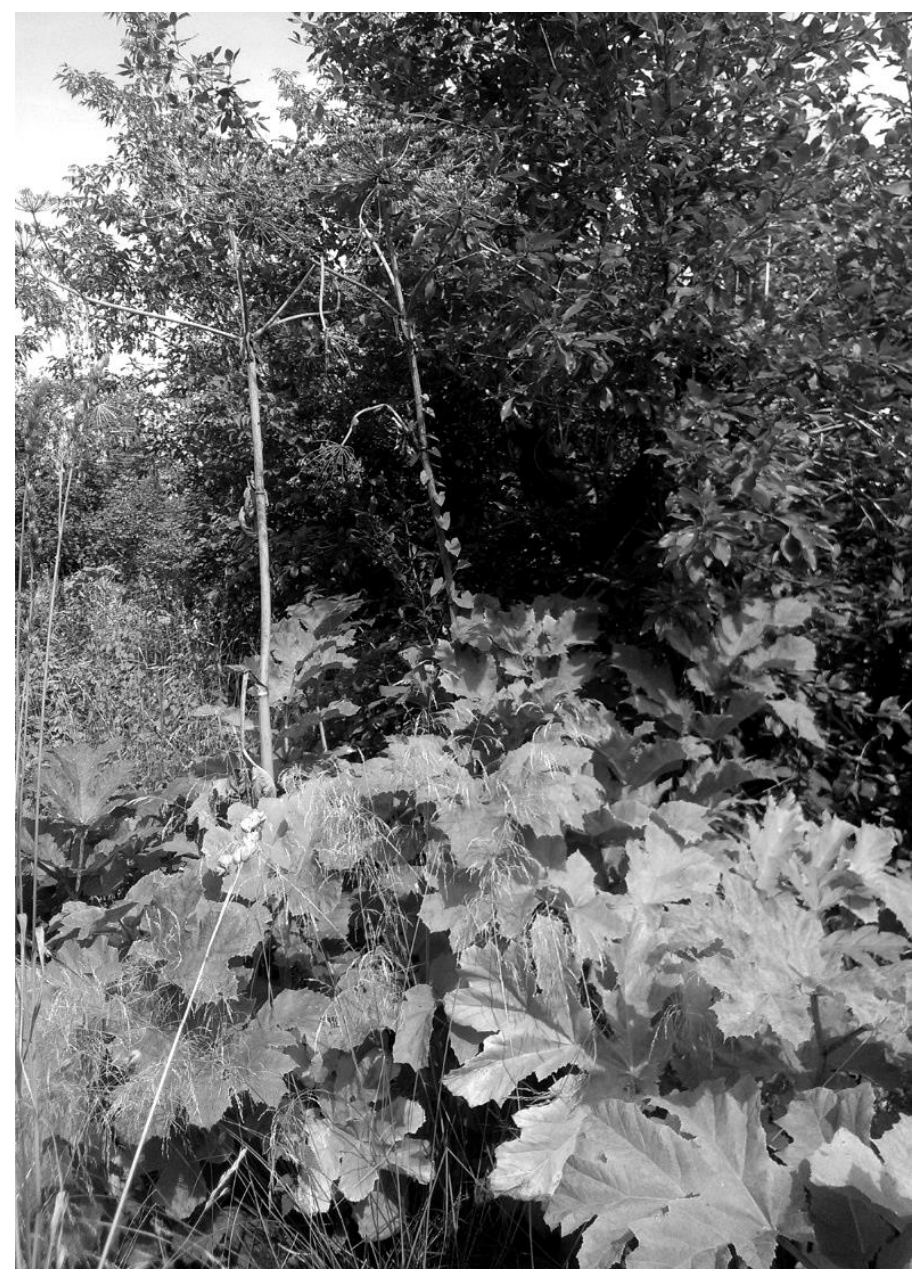

Fig. 2. Dense thickets of invasive plants Heracleum sosnowskyi in transformed habitat, Yekaterinburg city.

\subsection{Model native plants}

The seed germination of two native plants was studied: Festuca rubra L. (red fescue) and Trifolium repens L. (white clover). These species are typical native ruderal and meadow plants that growing on natural meadows and in urban habitats.

\subsection{Experiments}

For two vegetation experiments the F. rubra and T. repens were germinated in soils collected from: 1) habitat with dense thickets of invasive plants with urban soils (transformed habitat); 2) nearby habitat with same conditions without invasive plants with urban soils (non-transformed habitat); 3) old suburban meadow with sod-podzolic soils (meadow). 
Soil samples were collected in July. The soil was collected at a depth of 0-5 (7) cm; twigs, leaf debris and floor were not collected. Soil samples was sieved with $1 \mathrm{~cm}$ mesh. Containers were displayed in random order. Also, watering and seedling registration were carried out in random order. We put the collected unsterilized soil in containers $(25 \times 40 \times 10$ $\mathrm{cm}$ ) and then sowed 100 seeds of either F. rubra or T. repens in each container. Watering was about $60 \%$ of soil water holding capacity. We recorded seed germination at the 6-7-th days (tour I) and the 10th day (tour II).

The experiment with A. negundo was conducted in 2016. The soil was collected from six urban habitats in three sites with urban soils by the side of Yekaterinburg in the thickets of $A$. negundo or outside of them, in addition - in a meadow. The number of containers was 42 (for each of the three urban sites were 12 containers, that is, a total of 36 containers; additional 6 containers with soil from suburban meadow). Containers were exhibited at the greenhouse with a polycarbonate covering.

The experiment with $H$. sosnowskyi was conducted in 2017. The soil was collected from two sites (abandoned fields) in the thickets of H. sosnowskyi or outside of them, in addition - on a meadow. The number of containers was 16 (from each of 2 fields were 6 containers, that is, a total of 12 containers; additional 4 containers with soil from suburban meadow). Containers were exhibited at the open ground and only from above (not from the sides) were they covered with polycarbonate shields.

\subsection{Analysis of soil chemical properties}

In soil samples of topsoil layer (one from each site) were identified the $\mathrm{pH}_{\mathrm{H} 2 \mathrm{O}}$. The absorbed $\mathrm{Ca}^{2+}+\mathrm{Mg}^{2+}$ content was estimated by Kappen method, mobile phosphorus and potassium compounds were estimated by Kirsanov method, readily hydrolyzable nitrogen content was estimated by the Cornfield method. All measurements were performed at the analytical laboratory of FSBIS 'Ural research institute of agriculture'.

\subsection{Statistical analysis}

For the data analysis, we used general linear model (GLM, including ANOVA: STATISTICA 10.0; StatSoft, USA, 2011), the observation unit (replication) was the germination value (quantity of germinated seeds) in one container. The species of invasive plant (A. negundo or H. sosnowskyi), the species of model plant (F. rubra or T. repens), variant of habitat (transformed or non-transformed habitat and meadow), and tour of accounting (tour I or tour II) were considered as factors.

In GLM with hierarchically nested factors, the influence of local features of specific sites was additionally taken into account. In this case, the factor 'sites' was considered as nested in the factor 'variant of habitat'. The germination values were previously arcsine transformed. After the sign ' \pm ' follows the standard error value $(S E)$. All differences were considered statistically significant at $p<0,05$.

\section{Results and discussion}

The disparities in the main chemical properties of soil $\left(\mathrm{pH}_{\mathrm{H} 2 \mathrm{O}}\right.$, absorbed $\mathrm{Ca}^{2+}+\mathrm{Mg}^{2+}$ content, mobile phosphorus and potassium compounds, readily hydrolysable nitrogen, $\mathrm{N}$ ) between soils from transformed and non-transformed habitats were not noticed (Table 1). Therefore, the properties of soils from transformed and non-transformed habitats were comparable. 
Table 1. Agrochemical soil properties.

\begin{tabular}{|c|c|c|c|c|c|c|}
\hline Variant of soils & $\mathrm{N} \mathrm{mg} \mathrm{kg}^{-1}$ & $\mathrm{pH}$ & $\mathrm{SOC}, \%$ & $\begin{array}{c}\mathrm{Ca}^{2+}+ \\
\mathrm{Mg}^{2+} \\
\mathrm{mEq} \\
100 \mathrm{~g}^{-1}\end{array}$ & $\begin{array}{c}\mathrm{P}_{2} \mathrm{O}_{5} \\
\mathrm{mg} \mathrm{kg}^{-1}\end{array}$ & $\begin{array}{l}\mathrm{K}_{2} \mathrm{O} \\
\mathrm{mg} \mathrm{kg}^{-1}\end{array}$ \\
\hline \multicolumn{7}{|c|}{ The experiment in 2016; invasive plant - Acer negundo } \\
\hline \multicolumn{7}{|l|}{ Urban soils } \\
\hline $\begin{array}{l}\text { dense thickets of } \\
\text { A. negundo }\end{array}$ & $125 \pm 18$ & $6.53 \pm 0.16$ & $4.25 \pm 0.11$ & $44.7 \pm 4.4$ & $903 \pm 320$ & $274 \pm 92$ \\
\hline $\begin{array}{l}\text { out of } A \text {. negundo } \\
\text { thickets }\end{array}$ & $128 \pm 13$ & $6.15 \pm 0.62$ & $4.32 \pm 0.18$ & $42 \pm 6.8$ & $283 \pm 2$ & $180 \pm 33$ \\
\hline $\begin{array}{l}\text { Suburban meadow with } \\
\text { sod-podzolic soils }\end{array}$ & 216 & 5.47 & 5.00 & 45 & 82 & 112 \\
\hline \multicolumn{7}{|c|}{ The experiment in 2017; invasive plant - Heracleum sosnowskyi } \\
\hline \multicolumn{7}{|l|}{ Field soils } \\
\hline $\begin{array}{l}\text { dense thickets of } \\
\text { H. sosnowskyi }\end{array}$ & $164 \pm 36$ & $5.51 \pm 0.18$ & $4.44 \pm 0.25$ & $33.3 \pm 3.4$ & $171 \pm 20$ & $325 \pm 72$ \\
\hline $\begin{array}{l}\text { out of } H \text {. sosnowskyi } \\
\text { thickets }\end{array}$ & $132 \pm 44$ & $5.68 \pm 0.21$ & $4.75 \pm 0.53$ & $32 \pm 7.6$ & $158 \pm 41$ & $100 \pm 34$ \\
\hline $\begin{array}{l}\text { Suburban meadow with } \\
\text { sod-podzolic soils }\end{array}$ & $237 \pm 10$ & $5.88 \pm 0.05$ & $5.18 \pm 0.11$ & $46.9 \pm 0.4$ & $251 \pm 13$ & $142 \pm 37$ \\
\hline
\end{tabular}

The summarized analysis of both experiments results using four factor ANOVA (factors: soil variant, species of invasive plant, species of model plant, tour of accounting) with full cross-over interaction between factors showed that effect of soil variant was not considerable but statistically significant (Table 2). Germination also depended on all other factors: species of invasive plant, species of model plant, tour of accounting. Significant interactions were few.

The greatest germination was on the soil of a suburban meadow on average (Fig. 3, A). On the 10th day F. rubra on average had lowest germination in variant with soil from transformed habitat $(55 \pm 3 \%)$, and highest in soil collected from the meadow $(66 \pm 4 \%)$ in both experiments. The average seed germination of T. repens in both experiments on the 10th day was $47 \pm 7 \%$ in soil from transformed habitat and $58 \pm 12 \%$ in soil from meadow. However pairwise estimation of differences in the final estimate of germination (i.e. at the 10 th day) by Tuckey's test showed no significant differences among variants.

Germination of native plants contrast differed in the experiments of 2016 and 2017, i.e. when testing the allelopathic effects from $A$. negundo and $H$. sosnowskyi, respectively (Fig. 3 , B). In 2016 (the experiment with $A$. negundo) the average germination was $45 \pm 3 \%$ on the 10th day, and in 2017 (the experiment with $H$. sosnowskyi) $-73 \pm 4 \%$. The average germination over the 2 years of $F$. rubra and T. repens differed slightly (Fig. 3, C), as well as the average germination in different accounting tour (Fig. 3, G).

The effect of variant (i.e. effect of invasive plants on seed germination) in three-way ANOVA (factors: soil variant, the species of model plant, tour of accounting) given the separate analysis of model native plants germination in soil from thickets of both $A$. negundo $\quad\left(F_{\text {variant }(2 ; 72)}=2.30 ; \quad P=0.1078\right)$ and $H$. sosnowskyi $\quad\left(F_{\text {variant }(2 ; 20)}=1.93\right.$; $P=0.1714$ ) was not significant. Also we could not confirm the effect of invasive plants on germination of $F$. rubra $\left(F_{\text {variant }(2 ; 46)}=2.54 ; P=0.0900\right)$ and $T$. repens $\left(F_{\text {variant }(2 ; 46)}=2.35\right.$; $P=0.1068$ ) in three-way ANOVA (factors: soil variant, species of invasive plant, tour of 
accounting). Thus, the general data analysis shows no effects of soils collected under $A$. negundo and $H$. sosnowskyi canopy on seed germination of the model native plants.

We supposed that soil effect of invasive plants is not reveal because it concealed by other factors effects. Thus additionally we have analyzed germination rate. Whereas, at first, we excluded the germination rate at the 6th and the 7th days and kept only germination rate at the 10th day. Secondly, we took into account each sites where soils were collected in each type of habitat, as an additional source of variability (GLM with hierarchical nested design).

This analysis design did not lead to a change in the estimates of the effects associated with the variant of treatment: whole model $\left(F_{\text {variant }(2 ; 40)}=2.62 ; P=0.0856\right)$; two species of model native plants in soils from the thickets of $A$. negundo $\left(F_{\text {variant }}(2 ; 32)=1.55\right.$; $P=0.2271)$; two species of model native plants in soils from the thickets of $H$. sosnowskyi $\left(F_{\text {variant }}(2 ; 8)=1.10 ; \quad P=0.3789\right) ; \quad F$. rubra in both experiments $\left(F_{\text {variant }}(2 ; 17)=1.96\right.$; $P=0.1710) ;$ T. repens in both experiments $\left(F_{\text {variant }(2 ; 17)}=2.06 ; P=0.1582\right)$.
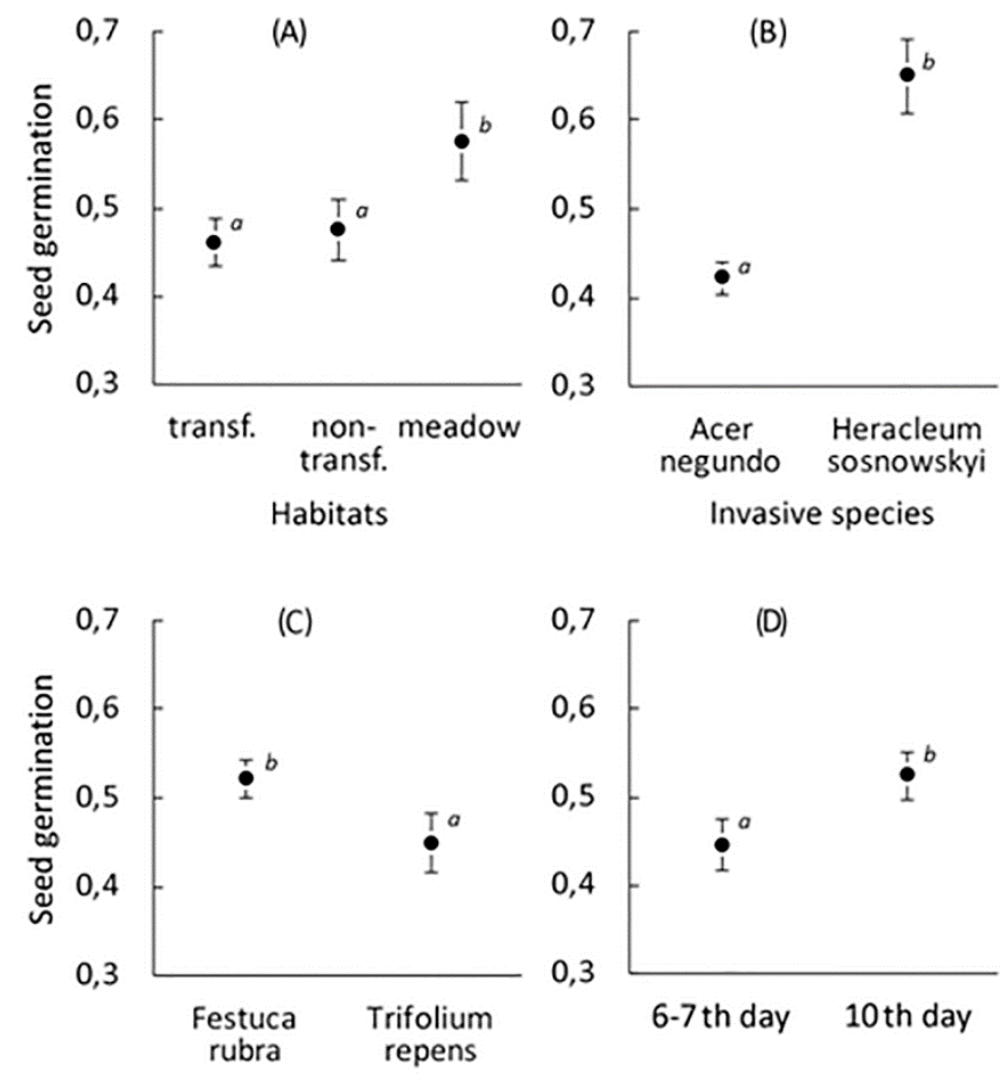

Model species

\section{Accounting tour}

Fig. 3. Average seed germination $(m \pm S E)$ during two accounting tours for Festuca rubra and Trifolium repens in soils transformed by Acer negundo and Heracleum sosnowskyi subject to variant of habitat (A; transf. - transformed habitats; non-transf. - non-transformed habitats; meadow suburban meadow); species of invasive plant (B); species of model plant (C); tour of accounting (D). Homogeneous subsets for each figure are denoted by the same letters (Tukey's test, $P<0.05$ ). 
In all cases, slightly increased germination was in the soil of suburban meadow (Fig. 4). The germination in soils from invasive plants thickets was slightly worse. But significant pairwise contrasts between transformed and non-transformed habitats have not been established.

In our study, direct environmental and competitive factors from the vegetating plants of $A$. negundo or $H$. sosnowskyi were excluded. Therefore the effect of A. negundo and $H$. sosnowskyi on seed germination of native plants was only indirect i.e. it depended on changes in soil properties.
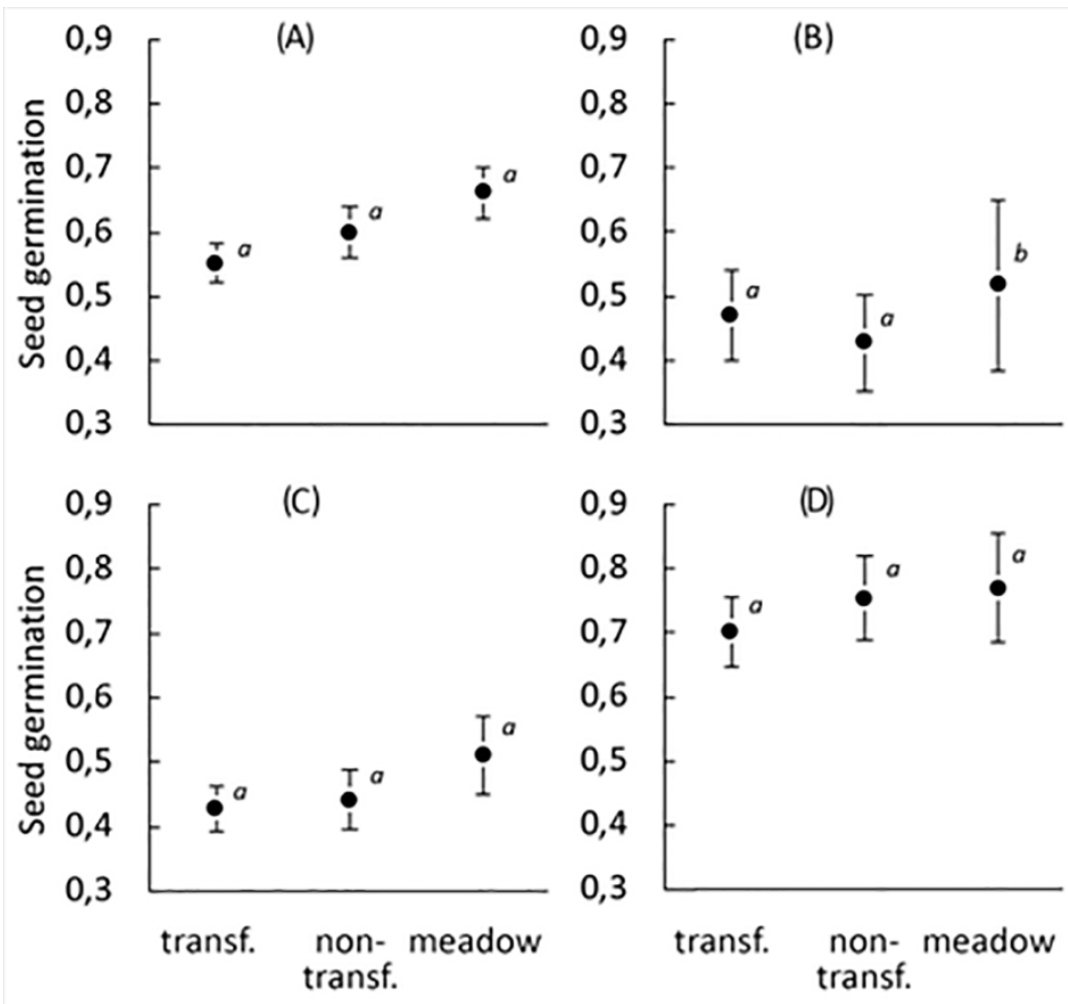

Habitats

Fig. 4. Average seed germination $(m \pm S E)$ on the 10th day for Festuca rubra (A) and Trifolium repens (B) and for two model native plants in 2016 (C) and 2017 (D) subject to variant of habitat (transf. - transformed habitats; non-transf. - non-transformed habitats; meadow - suburban meadow). Homogeneous subsets for each figure are denoted by the same letters (Tukey's test, $P<0.05$ ).

According to our data, there are stronger reasons for the variation of model native plants germination than the invasive plants transformation of habitats. The comparison of nearby areas with or without dense thickets of invasive plants showed no contrast difference in germination. Slight suppression of germination was peculiar to urban soils or deeply transformed anthropogenic habitats in comparison with soils from suburban meadow regardless to invasive plants presence. Maximum variation of germination values was related with differences between experiments in 2016-2017.

Although in 2016 we investigated the activity of A. negundo and in 2017 H. sosnowskyi, this can hardly explain the features of different year's results. It is important that the experiments of 2016 and 2017 were conducted in different conditions - in the 
greenhouse in 2016 and in the open space in 2017. Modes of temperature, humidity and other factors were, respectively, different. Therefore, it remains unknown what proportion of the interannual variance of germination was associated with the peculiarities of A. negundo and $H$. sosnowskyi influence, and what proportion was associated with differences among other conditions.

We concluded that the soils under A. negundo and $H$. sosnowskyi canopies does not inhibit F. rubra and T. repens germination, it is weakly corresponded to the other effects that observed in A. negundo and H. sosnowskyi invasions, such as reducing indigenous plants diversity [21]. Note that the reduced abundance of native plants in the thickets of $A$. negundo is confirmed in our areas: there were about 2-8 species of native plants in A. negundo habitats and about $10-15$ species in habitats where $A$. negundo was absent. It is interesting that species diversity in soil seed bank did not differ regardless to where the soil was collected: in the thickets of $A$. negundo or outside of them [22].

Intuitively, the conclusion that the soils under $A$. negundo and $H$. sosnowskyi canopies have no effects on germination of model native plants does not agree with the part published estimates of allelopathic activity for $A$. negundo $[9,10,11]$ and $H$. sosnowskyi $[13,14,15]$. But, first, allelopathic activity of invasive plants is sometimes not confirmed $[6,23]$ and, secondly, it is possible that the divergence between our results and published estimates is understandable and associated with the methodological features of different studies. For example, the inhibitory effect of A. negundo was shown using water extract from leaves $[9,10]$ or from soil [11].

We used the soil directly from the thickets of invasive plants, not the extracts. It is known that water extracts from the leaves of $A$. negundo and from the soils under this plant may have different activity due to soil biota [24, 25]. And it is not surprising that the inhibitory effect of soil extracts on the test plants is less than the leaf extracts [11].

Another important reason for the variability of allelopathic effects is the speciesspecifity of test plant responses. For example, it has been established wide range of substances effects from seeds and xylem sap of $H$. sosnowskyi on different types of herbs [13]. In this experiment, the variability of responses was manifested even in connection with cultivars species of test plants. In another study [15] it has been shown that the exudates from the fruits of $H$. sosnowskyi had little effect on the germination of Lolium multiflorum (Poaceae) and Trifolium repens (Fabaceae) and more strongly effect on the Lactuca sativa (Asteraceae) and Raphanus sativa (Brassicaceae). Allelopathic activity of A. negundo was previously tested on species from Brassicaceae family: Sinapis alba [9, 10] and Raphanus sativus [11]. Thus, it is possible that in our experiment allelopathic activity soils from invasive plants did not manifest itself due to the partial resistance of model native plants from Poaceae and Fabaceae families.

Theoretically, the change in the germination of native plants, if we observed it, could be due to the accumulation of chemical nature inhibitors in soils or the influence of pathogens. However, since the activity of the soil under $A$. negundo and $H$. sosnowskyi canopies is not confirmed, there is no need to discuss the mechanisms of such activity.

Our results indicate either a complete absence or only a small negative effect at the seed germination of $F$. rubra and $T$. repens seeds in soils collected from invasive plants thickets. The germination inhibition of the native plants in soils from the transformed habitats is not large in relative values $5-10 \%$. The decrease in the germination of native plants in soils from transformed habitats is statistically confirmed only in comparison with soil from suburban meadow, but not in comparison with the soils from other urban or agricultural habitats.

Thus, our hypothesis was not confirmed. Allelopathic effects of $A$. negundo and $H$. sosnowskyi acting through soil transformation are negligible. The ecological importance of 
these effects is improbable. However, this result does not exclude the role of direct allelopathic effects co-acting with precipitations that penetrate through canopy cover and leaf-litter into soils.

\section{Conclusions}

The new knowledge as a result of our work is that we did not receive confirmation of the allelopathic activity of $A$. negundo and $H$. sosnowskyi transmitted through the soil. This broadens the concept of the allelopathic abilities of these invasive plants important in Eurasia. Their allelopathic activity is probably largely limited by the activity of extracts from leaves. According to our estimates, the deep transformation of the chemical properties of soils in the thickets of $A$. negundo and $H$. sosnowskyi does not occur.

The applied relevance of our results is prompting suggestions that the potential ability of plant communities to recover in the habitats transformed by $A$. negundo and $H$. sosnowskyi does not differ qualitatively from the restore ability of communities disturbed for other reasons. The soils under $A$. negundo and $H$. sosnowskyi canopies are likely not to accumulate substances or pathogens that significantly inhibit the development of native plants. Therefore, in case removing of invasive plants and their soil seed banks, succession suppressed by $A$. negundo and $H$. sosnowskyi are likely to continue to go to the zonal type.

\section{Acknowledgments}

This work was carried out within the state assignment of IPAE UB RAS and was supported by FSR program of Institute Botanic garden UB RAS. Authors thank FSBIS 'Ural research institute of agriculture' for the analysis of soil chemical properties.

\section{References}

1. J.A. Nielsen, R.D. Frew, P.A. Whigam, R.M. Callaway, K.J.M. Dickinson, Allelopathy J., 35 (2015)

2. M. Dorning, D. Cipollini, Plant Ecol., 184 (2006)

3. D. Cipollini, C.M. Rigsby, E.K. Barto, J. Chem. Ecol., 38 (2012)

4. R.M. Callaway, G.C. Thelen, A. Rodriguez, W.E. Holbe, Nature, 427 (2004)

5. K.A. Stinson, S.A. Campbell, J.R. Powell, B.E. Wolfe, R.M. Callaway, G.C. Thelen, S.G. Hallett, D. Prati, J.N. Klironomos, PLOS Biol., 4 (2006)

6. A.M. Glushakova, A.V. Kachalkin, I.Yu. Chernov, Eurasian Soil Sci., 48 (2015)

7. J.N. Klironomos, Nature, 417 (2002)

8. W.H. Putten, R.D. Bardgett, J.D. Bever, T.M. Bezemer, B.B. Casper, T. Fukami, P. Kardol, J.N. Klironomos, A. Kulmatiski, J.A. Schweitzer, K.N. Suding, J. Van de Voorde, D.A. Wardle, J. Ecol., 101 (2013)

9. A. Csiszár, Acta Silv. et Lignaria Hungarica, 5 (2009)

10. Csiszár, A., Korda, M., Schmidt, D., Šporcic, D., Süle, P., Teleki, B., Tiborcz, V., Zagyvai, G. \& Bartha, D. Allelopathy J., 31 (2013)

11. Yu.A. Yeryomenko, Russ. J. Biol. Invasions, 5 (2014)

12. L.Yu. Yourlova, D.M. Chernya, O.P. Koutovaya, Pacific Medical Journal, 2 (2013) (In Russian).

13. M.N. Kondratiev, S.N. Budarin, Yu.S. Larikov, News of Timiryazev Agricultural Academy, 7 (2015) 
14. M. Mishyna, N. Laman, V. Prokhorov, Y. Fujii, Nat. Prod. Commun., 10 (2015)

15. M. Mishyna, T.T. Van Pham, Y. Fujii, Allelopathy J., 42 (2017)

16. M.V. Kostina, O.I. Yasinskaya, N.S. Barabanshchikova, F.A. Orlyuk, Russ. J. Biol. Invasions, 7 (2016)

17. Yu.K. Vinogradova, S.R. Mayorov, L.V. Horun, The Black Book of the flora of Central Russia: invasive plant species in ecosystems of Central Russia (Moscow, 2010)

18. A.A. Khapugin, Hacquetia, 18/2 (2019)

19. M. Djukic, D.D. Bojovic, M. Grbic, D. Skocajic, D. Obratov-Petkovic, I. Bjedov Fresenius Environ. Bull., 22/2A (2013)

20. L. Zihare, R. Soloha, D. Blumberga, Agron. Res., 16/3 (2018)

21. A.V. Emelyanov, S.V. Frolova, Russ. J. Biol. Invasions, 2 (2011)

22. D.V. Veselkin, O.A. Kiseleva, E.D. Ekshibarov, O.S. Rafikova, A.A. Korzhinevskaya, Russ. J. Biol. Invasions, 9 (2018)

23. V. Chobot, C. Huber, G. Trettenhahn, F. Hadacek, J. Chem. Ecol., 35 (2009)

24. Y-P. Li, Y-L. Feng, Y-J. Chen, Y-H. Tian, Sci. Bull., 60 (2015)

25. X. Zhu, J. Zhang, K. Ma, PLOS One 6, e25393 (2011) 